\title{
A Congenital Alar Defect and Its Reconstruction
}

\author{
Mehmet O. YENIDÜNYA ${ }^{1}$, Nyoman RIASA ${ }^{2}$
}

${ }^{1}$ Department of Plastic Reconstructive and Aesthetic Surgery and Burn Unit, School of Medicine, Uludağ University, Bursa, Turkiye.

${ }^{2}$ Department of Plastic Reconstructive and Aesthetic Surgery and Burn Unit, School of Medicine, Udayana University, Bali, Indonesia.

\section{ABSTRACT}

Congenital anomalies of the nose are very rare and include the bifid nose, complete absence of the nose, and unilateral absence of the nose.

A 23-year-old medical school student was diagnosed with a rare congenital nasal anomaly including left alar full-thickness defect.

Under general anesthesia, a posteroinferiorly based V-Y flap was selected to cover the outer surface. To make the inner lining, another anteroinferiorly based V-Y flap from the internal coverage tissue was elevated, including alar cartilages remnants and soft tissues around it. These two V-Y flaps were called double-opposing V-Y flaps. To support the alar wing, a cartilaginous graft was inserted taken from the anterior septal edge.

The treatments of the nasal alar defects resulting from oncological surgery and those from congenital anomalies significantly differ. The expectations of the patients from the surgery are higher in the second situation than in the first one. A technique using minimal donor site morbidity should be searched.

Key words: Congenital defects of the nose, forehead flap, nasolabial flap, V-Y advancement flapo

\section{INTRODUCTION}

The development of the face occurs mainly between the fourth and eighth weeks. By the end of the fourth week, bilateral oval thickenings of the surface ectoderm, called nasal placodes, develop on each side of the inferior part of the frontonasal prominence. The frontonasal prominence forms the forehead, dorsum of the nose, and apex of the nose. The alae of the nose are derived from the lateral nasal prominences (1).

Congenital anomalies of the nose are not so common. As a common congenital nasal problem, cleft lip nose deformity is not considered a pure nasal anomaly; it accompanies the cleft lip, and can be considered a part of it.

\section{CASE AND OPERATION}

A 23-year-old medical school student, after attending a lecture in his educational program entitled "The nose as an organ in reconstructive surgery" given by a senior surgeon, sought consultation on his congenital defect on the left nasal ala (Figures 1 and 2). His history revealed that he was worried about the possibility of a visible scar following operations and that was why he was not operated till that day. Under general anesthesia, an inferiorly based V-Y flap was selected to cover the outer surface (Figure 3a). To make the inner lining, another anteroinferiorly based V-Y flap from the internal coverage tissue was elevated, including alar cartilages remnants and soft tissues around it. These two V-Y flaps were called 


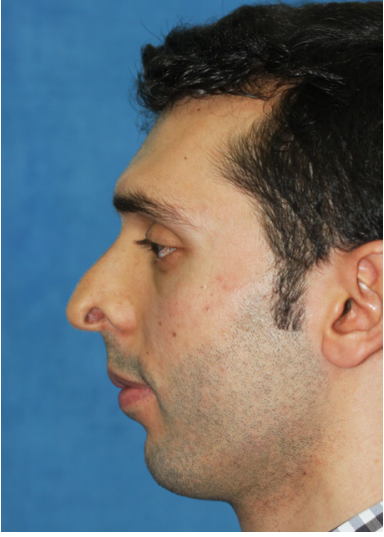

FIGURE 1: Profile picture of the patient.

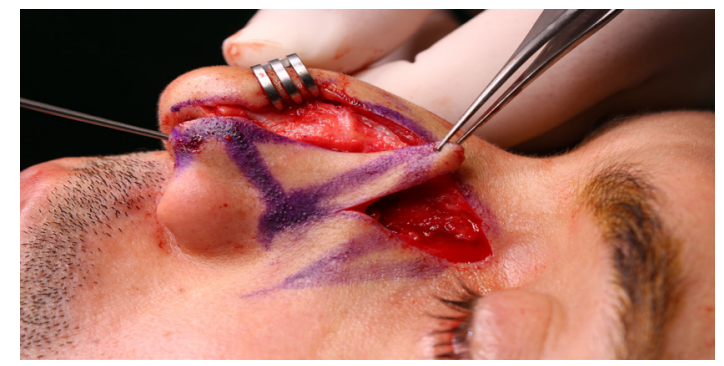

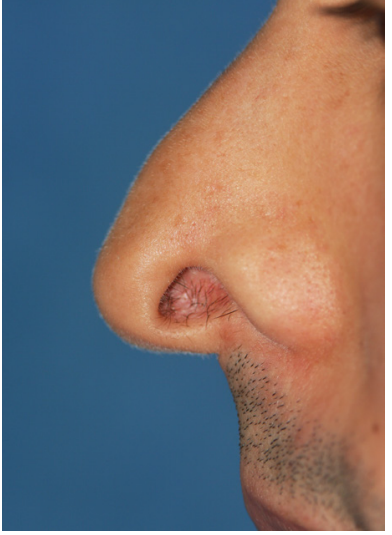

FIGURE 2: Close-up appearance of the congenital defect.

FIGURES 3a and 3b: An posteroinferiorly based V-Y advancement flap was planned with a cartilage graft from the anterior septal edge. For the inner lining, an anteroinferiorly based V-Y flap was advanced in the caudal direction.

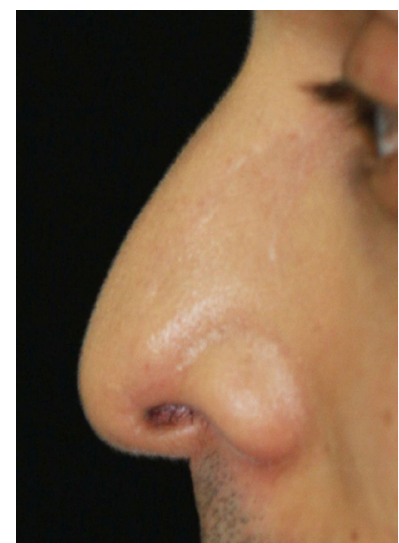

FIGURE 4: Postoperative close-up appearance.

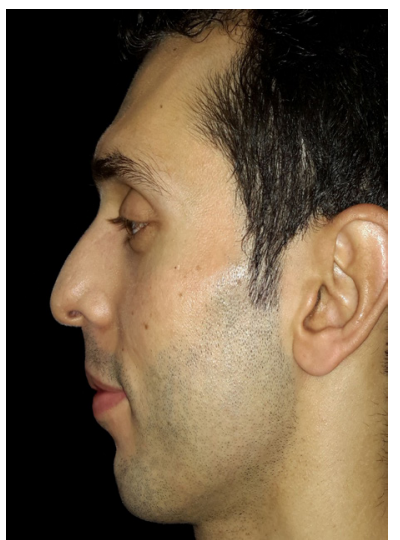

FIgURE 5: Postoperative profile on the operated side.

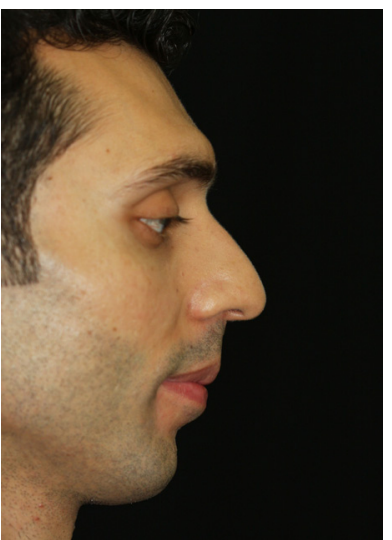

FIGURE 6: Normal side for comparison. double-opposing V-Y flaps (Figures 3b). To support the alar wing, a cartilaginous graft was inserted taken from the anterior septal edge. The postoperative result was uneventful (Figures 4-6).

\section{DISCUSSION}

Congenital anomalies of the nose are very rare and include the bifid nose, complete absence of the nose, and unilateral absence of the nose (2). Only one study on these anomalies could be found in the literature (3). The study included two cases, and the problem was defined as the congenital notch of the alar. It was located on the left side, as in the present case.

From a surgical point of view, The treatments of the nasal alar defects resulting from oncological surgery and those from 
congenital anomalies significantly differ. The expectations of the patient from the surgery are higher in the second situation than in the first one. The patient is familiar with his or her problem in the second situation, whereas in the first condition, the problem is expected by both the surgeon and the patient to worsen if not treated properly. Just the opposite is true for the congenital problems, where the surgeon and the patient are sure that the congenital anomaly of the alae nasi will not progress further.

It is logical to expect the parents to seek a treatment for the congenital defect in their child during initial stages. On the contrary, they are aware of the risks including some bad scars. It can be said that the smaller the defect, the more is the fear that complications may exist. Also, if no other existing problem is associated with a small alae nasi defect in a child, even his or her parents may neglect it. Once the child grows up, the patient himself or herself may look for reconstructive options. The present case was a similar one. The patient was a fifth-year medical school student, and after completing his plastic surgery program, he decided to go for surgery.

The available reconstructive options include a superiorly based nasolabial flap selection that is common in practice to reconstruct ala nasi defects (4). The superiorly based nasolabial flap can also be used by folding to cover both inner and outer surfaces (5).

A figurative case was found without any pictures but with only drawings in a chapter entitled "Deformities of the lining of the nose and full-thickness loss of nasal tissue" by Converse. The legend of the figure was as follows: "Figure 29-222: Congenital deformity. Retracted ala due to short lateral nasal wall." However, in his line drawing Converse presented his method with a V-Yshaped design, but instead of $Y$ closure, a full-thickness skin graft from the postauricular area was mentioned (6). In the present case, the donor area could be closed with a Y closure after the same advancement flap. The same book and the same chapter included many other line drawings for nearly same pathologies with different etiologies. It was difficult to understand whether the deformity was so common that the author himself felt uneasy to print a picture or no case like this existed and all of them were just imaginations. At this point, one should realize that Converse was recognized among the most famous 10 plastic surgeons through his work $(7,8)$.
Another illustrated case was related to the congenital absence of the nostril margin, which was corrected by a composite graft from the helix margin, as mentioned in another textbook on plastic surgery (9).

Two patients with trigeminal trophic syndrome causing the alar defect on the nose were treated with a paramedian forehead flap combined with a nasolabial flap. The syndrome presented as a triad of trigeminal sensory impairment, altered sensations of the trigeminal sensory territory, and a crescent-shaped ulceration of the nasal ala caused by self-manipulation (10).

A V-Y advancement flap from the cheek is the main body of a flap that is combined with a turnover flap from the nasolabial fold to reconstruct full-thickness ala nasi defects, especially in elderly patients (11).

As a different designed flap for reconstructing the ala nasi and the perialar region, the shark flap has been reported in the literature; however, it has been used to close very small defects (12).

For reconstructing partial-thickness circular defects, a skin helix flap on the nasal ala has been described (13). The helix skin flap and the shark island flap are similar except the nasolabial extended portion of the shark island flap.

Trigeminal trophic syndrome may cause full-thickness alar defects on the nose resembling the present case. Two cases with trigeminal trophic syndrome were presented by reconstructing a combination of the paramedian flap and the nasolabial flap. Between the two flaps, an auricular chondrocutaneous composite graft was inserted (14).

Nasolabial perforator flaps can also be used for one-stage reconstruction of defects after removal of malignancies in the nasal area (15).

\section{REFERENCES}

1. Moore KL. The Developing Human Clinically Oriented Embryology, 4th edition, Philadelphia: W B Saunders, pp 189194, 1988.

2. Wang $\mathrm{MKH}$, Congenital anomalies of the Nose, In: Converse JM, ed. Reconstructive Plastic Surgery, Philadelphia: W B Saunders, 1977; 1178-1184.

3. Moritsch E. Correcture of congenital defects of the wing and the tip of the nose. Laryngol Rhinol Otol 1977; 56(3):223-228. 
4. Javaid M, Ahmad N, Khan Q. et al. outcome of nasolabial flap in reconstruction of the nasal alar defect. J Med Sci 2011; 19(4): 163-166.

5. Jovanović $M$, Colić $M$, Rasulić $L$, Stojičić $M$, Mališ $M$. Rekonstrukcija ale nosa preklopljenim nazolabijalnim režnjem, Acta Chirurgica Iugoslavica, pp 29-32, 2007.

6. Converse JM. Deformities of the Lining of the nose- Full thickness loss of nasal tissue. In: Converse JM, ed. Reconstructive Plastic Surgery, Philadelphia: W B Saunders, 1977; 1199-1287.

7. Hallock GG. The plastic surgeon of the 20th century. Plast Reconstr Surg 2001; 1014-1024.

8. Denadai R, Raposo Amaral CE. Undergraduate plastic surgery education: problems, challenges, and proposals. Ann Med Health Sci Res 2014; 4: 169-170.

9. Peet EW, Patterson TJS. The Essentials of Plastic Surgery. Blackwell, Baltimore, p 257, 1963.
10. Osaki Y, T Kubo T, Minami K, and Maeda D. Trigeminal Trophic Syndrome: Report of 2 Cases, www.eplasty.com, 2013; 509-513.

11. Feinendegen DL, Langer M., Gault D. A combined $V-Y$ advancement turnover flap for simultaneous perialar and alar revonstruction. Br J Plast Surg 53:248-250, 2000.

12. Pérez-Paredes MG, Narganes LMV, Cucunubo HA, Prieto MAR. Shark Island Flap for Reconstruction of Nasal Ala-Perinasal Defects, Actas Dermosifiliogr, pp 709-711, 2014.

13. Raccagni AA, Dondas A, Righini MG, Trevisan G. A skin helix flap to correct circular skin loss on the nasal ala. Acta Dermatoven APA, 2010; 11-14.

14. Osaki Y, Kubo T, Minami K, Maeda D. Trigeminal Trophic Syndrome: Report of 2 Cases. E-plasty, open access journal, 2013; 509-513.

15. Sohn WI, Choi JY, Jung SN. Reconstruction of nasal ala with nasolabial perforator flap after cancer removal. Head Neck Oncol. 2012; 30: 83-88. 